\title{
A New Location based Mechanism for Indoor Environments
}

\author{
Prof. B.B. Gite ${ }^{1}$, Swati Pandey ${ }^{2}$ \\ Head of Dept., Computer Dept., Sinhgad Academy of Engg Kondhawa, Pune, India ${ }^{1}$ \\ Student, Computer Dept., Sinhgad Academy of Engg Kondhawa, Pune, India ${ }^{2}$
}

\begin{abstract}
The new advances portraying the web of Things allow acknowledging genuine sensible situations prepared to offer propelled administrations to the clients. As of late, these sensible conditions additionally are being misused to revamp the clients' enthusiasm on the social legacy, by ensuring genuine intuitive social encounters. Amid this paper, we tend to style and approve an inside area mindful plan prepared to upgrade the client ability amid adiposity. Most importantly, the anticipated framework relies upon a wearable gadget that blends picture acknowledgment and Localization abilities to mechanically offer the clients with social substance related with the decided craftsmanships. The restriction information is acquired by a Bluetooth framework put in inside the Museum. In addition, the framework store interactive media framework substance made by the client and to share condition produced occasions on his/her interpersonal organizations.
\end{abstract}

Keywords: Bluetooth, Image recognition, IoT, Tracking system, Location-awareness, SoA, Smart Museum.

\section{INTRODUCTION}

Craftsmanship and culture have constantly assumed an imperative part in people lives. Throughout the hundreds of years, hundred of historical centers furthermore, workmanship displays have safeguarded our different social legacy furthermore, filled in as vital wellsprings of instruction and learning. Historical centers are these days a device of diversion, for example, theaters or films. Today, historical centers and craftsmanship displays typically furnish guests either with paper booklets or with sound guides. Visits at exhibition halls are regularly viewed as exhausting, since it is hard for exhibition halls guardians to get the consideration of travelers.

Specifically, it is hard to characterize ahead of time a visit for every one of the guests, since interests may fluctuate from individual to individual. Interests are not the same as kids to grown-ups, understudies amass from single guest, easygoing guest to affectionate guest. In this way, intuitive and customized historical center visits should be produced. In this point of view, a critical commitment can be given which includes the expansion of the Internet to little and lowcost "things" that are thought to acknowledge brilliant conditions in request to give new administrations to the clients.

\section{RELATED WORK}

In the writing, there are a few works tending to the previously mentioned issues, however none of them gives an adaptable furthermore, versatile arrangement that can tackle every one of the issues in one framework. As stated, one of the key elements of the proposition is spoken to by the indoor confinement component, which at present is an essential and testing research point. In [2], the creators display a customized shrewd control framework that: (i) restricts the client abusing the attractive field of the cell phone, and (ii) controls apparatuses show at the client's area. Another case of area mindful administrations in a brilliant condition is accounted for in [3].

Here, the creators propose a framework that gathers data from the condition and afterward gives administrations to enhance the way of life of the clients, fundamentally from an enthusiastic perspective. An intriguing arrangement is given in [4].

For this situation, the creators propose a get to control component, which comprises of a motor inserted into brilliant items ready to make approval choices by considering both client area information furthermore, get to qualifications.

Client area information are assessed utilizing attractive field measured and sent by the telephone. At long last, in [5, 6] creators show area mindful frameworks ready to restrict clients by abusing a foundation in light of the Bluetooth Low Energy innovation. At that point, the restriction data is used to adjust the home condition to the clients' needs. 


\section{IMPLEMENTATION}

This application is installed in the user's smart phone and used to obtain street bumps information. The street bumps detection has been developed in the Android platform. Once this app is initialized, it enables the location of the smart phone. User will login to application using login credentials. By entering username and password, user will login to application. If user is new, then he/she will have to register first. By filling all given details, user will get user name and password. Multiple users can login to application by registering process. After login, home page will be displayed. User will enter his/her requirements as shown in fig.1

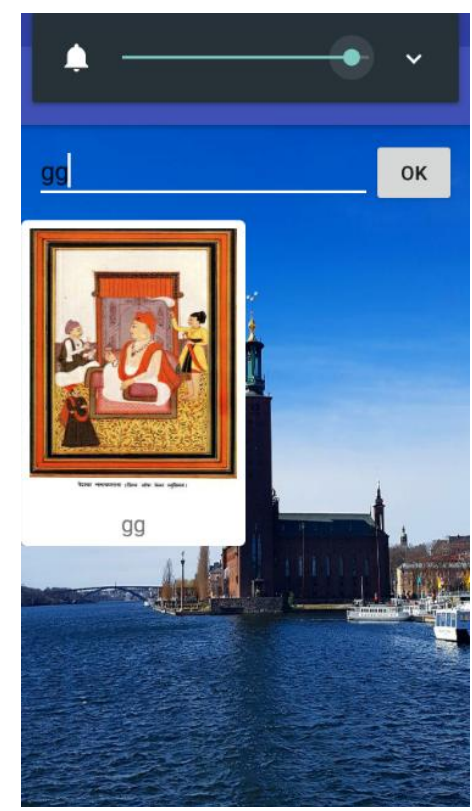

Fig. 1

After entering requirement, map will be loaded. Location of each thing is shown in map. It is shown in fig. 2

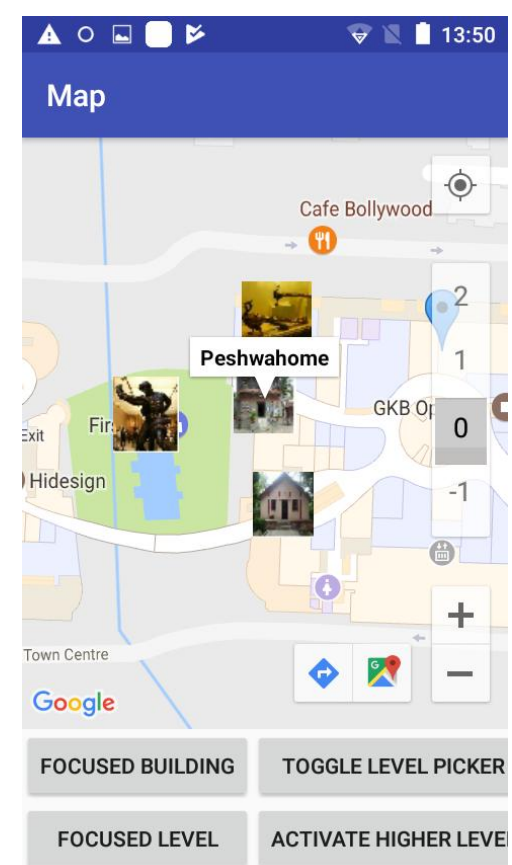

Fig. 2

Image matching process is done. We will verify things matching images with our database. After selecting particular thing, Information about image is displayed as shown in fig 3 


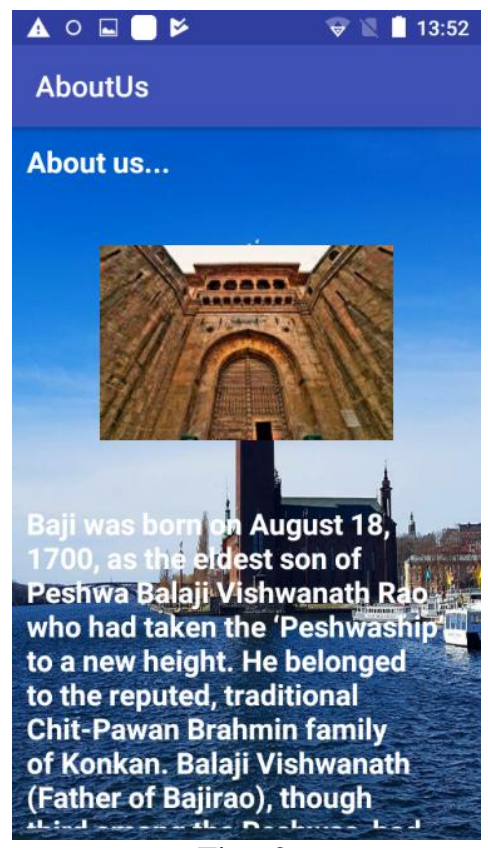

Fig. 3

\section{CONCLUSION}

In this work, an inside area mindful plan for savvy historical centers was planned and legitimate. In extra detail, the anticipated framework relies upon a wearable gadget furnished with picture acknowledgment and restriction abilities to mechanically offer clients with social substance related with the decided works of art. The ability to recognize the client's position is secure by relate degree framework of Bluetooth Low Energy transmitters. The outline also comprises of a procedure focus, wherever the specific business rationale is dependable to (i) recover from the Cloud the social information related with the decided fine arts and (ii) deal with the remaining of the indoor surroundings in understanding to clients' position.

\section{REFERENCES}

[1] M.V. Moreno, J.L. Hernandez, and A.F. Skarmeta, "A New Location-Aware Authorization Mechanism for Indoor Environments," in Proc. 28th International Conference on Advanced Information Networking and Applications, Victoria, 2014, pp. 791 - 796.

[2] L. Mainetti, V. Mighali, and L. Patrono, "An IoT-based User-centric Ecosystem for Heterogeneous Smart Home Environments," in Proc. 2015 IEEE International Conference on Communications, IEEE ICC 2015, London (UK), June 8-12, 2015.

[3] L. Mainetti, V. Mighali, L. Patrono, "A Location-aware Architecture for Heterogeneous Building Automation Systems," in 14th IFIP/IEEE Symposium on Integrated Network and Service Management, IM 2015, Ottawa (Canada), May 11-15, 2015.

[4] ! G. De Luca, P. Lillo, L. Mainetti, V. Mighali, L. Patrono, and I. Sergi, "The use of NFC and Android technologies to enable a KNX-based smart home," in Proc. 2013 International Conference on Software, Telecommunications and Computer Networks, SoftCOM 2013, 2013, Article number 6671904, pp.1-7.

[5] ! M. Jung, J. Weidinger, C. Reinisch, W. Kastner, C. Crettaz, A. Olivieri, and Y. Bocchi, “A Transparent IPv6 Multi-protocol Gateway to Integrate Building Automation Systems in the Internet of Things," in Proc. 2012 IEEE Int. Conf. Green Computing and Communications, Besancon, 2012, pp. $225-233$.

[6] ! M. Jung, C. Reinisch, and W. Kastner, "Integrating Building Automation Systems and IPv6 in the Internet of Things," in Proc. Sixth Int. Conf. Inn. Mobile and Internet Services in Ubiquitous Computing, Palermo, 2012, pp. 683 - 688. 